\title{
Information flow in agriculture - through new channels for improved effectiveness
}

\author{
Mihály Csótó ${ }^{1}$
}

\section{N F O}

Received 19 Oct. 2010

Accepted 24 Nov. 2010

Available on-line 30 Nov. 2010

Responsible Editor: K. Rajkai

Keywords:

ICT-adoption, agriculture

\begin{abstract}
$\underline{\text { A B S T R A C T }}$
Agriculture has undergone significant changes since the industrial revolution. The industrial age and the market economy have moulded agriculture in their image just as much as the characteristics and tools of the information age have recently been transforming its previous operation. Information and communication technology (ICT) take-up in agriculture remains low, and the reasons behind this barely changed in the last 20-30 years. Information technologies are regarded as mediating channels and a vehicle for new services. It is important to research the various aspects of adoption of new information technology, and also not only the use, but the "effective use" of it (Gurstein, 2003). Information-intensive agriculture is fundamentally determined by information, knowledge and the decision-making farmers, in effect the human factor; therefore, studies aimed at the improvement of the situation of agriculture with ICT tools must be centred on the human element.
\end{abstract}

\section{Introduction}

Information has a central role in our modern way of living and agriculture is no exception: to be successful in farming requires gaining, processing, using and evaluating a huge amount of information (policy, markets, new methods etc.). Farmers are working in an information-intensive environment and numerous studies have showed that information and communication technologies (ICT) can play a vital role in realizing benefits with more effective information management in the farm level.

The supply chain in agriculture not only means the flow of products and income but also that of information (Niderhauser et al., 2008). The toolkit of the information society, information communication technologies (ICT) offers new opportunities for efficient operation, decision-making and adaptation to the environment (Herdon, 2009). This, however, can only work successfully if certain conditions are met. The potential opportunities can only be exploited to an optimum under the right circumstances, and it is also important that they are harmonised with the previously used farm management practice, or else the muchawaited success will suffer.

The purpose of the study is to identify the barriers of widespread adoption of ICT among farmers, mainly analyzing the information flow, information strategies, information literacy and the characteristics of the farm and the farmer. The author provides an overview of the literature and sets up a theoretical framework of the factors affecting the information strategies (and therefore also the use of ICT) of the farmers.

\section{Information flow and the farm manager}

Agriculture has undergone significant changes since the industrial revolution: one of the most important ones is market orientation (strictly speaking in the developed world we can only find farms producing for the market or at least partly for the market), but standardised solutions, economies of scale and automation have also become widespread, and this is only partly the result of the flow of the labour

${ }^{1}$ Mihály Csótó

BME-Information Society Research Institute, 1111 Budapest, Stoczek utca 2-4. 1/108. csoto.mihaly@ittk.hu 
force into the cities. The industrial age and the market economy have moulded agriculture in their image just as much as the characteristics and tools of the information age have been transforming its previous operation. At the same time, the fundamental cyclical nature of agricultural operation is unchanged. In order to shape, form and refine raw nature industrial characteristic have come to dominate agriculture which is now one of the industries.

Farming has been placed in a new framework these days: farm managers have had to increasingly devote attention and interact with the external world (environmental effects, quality requirements, standards, and documentation) - see for example the documentation necessary when applying for EUfunds. Besides land, labour and capital, sufficient information has become a critical factor for agricultural businesses. Agricultural management and producers are both dependent on a comprehensive, informationrich environment, since without it they could easily lose their competitive edge.

Modelling the agricultural decision-making process and information flow is nothing new. The primary objective of studies aimed at creating models is to determine why a given group of farmers behave the way they do (Gladwin, 1989). With the help of models support and knowledge that contribute to more efficient operation and better decision-making can be provided for farmers.

Information and knowledge are inseparable since the most important input in decisions originates from the stratum of information (i.e. given potentials, already acquired knowledge, and finding additional information necessary for making decisions). Information flow, or the lack of it, as well as its intensity and knowing about the circumstances of a given farm and its manager might provide a comprehensive picture about the decision-making process and thus the character of a farm.

Sörensen and his associates (2010) conducted interviews and based on them drew the following information cloud around the farm manager, a so-called rich picture of factors that influence and shape decisions (Figure 1.).

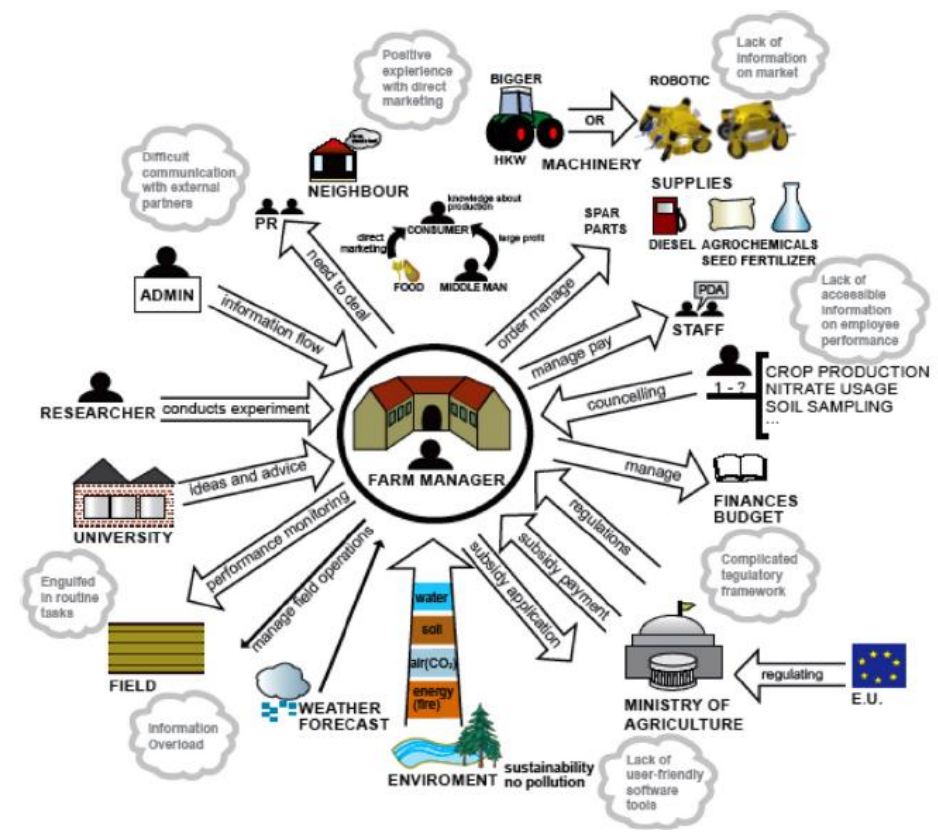

Figure 1. Farm management, the "rich picture" (Sörensen et al., 2010)

Important factors for the decision-maker of a farm to find his way in the above information environment not only include the numerous opportunities for interaction and information sources but also the used channels and the quality of information. 


\subsection{The quality of information and used channels}

In a traditional approach information channels can be grouped into:

- Personal network (suppliers, extension service, other farmers, markets, events)

- Printed media (books, encyclopaedias, maps, almanacs, newsletters, advertisements)

- Electronic media (TV, radio, websites, databases, services on cell phone, remote sensing)

In the last group the Internet must be highlighted as a special entity that can equally be a number one source (databases, consultancy web services, electronic administrative services) or a secondary intermediary of printed or electronic media (e.g. IPTV, video TV) and a means of personal communication.

Most sources agree that combined sources are generally the most effective, or those that fit in with the previous information-acquisition practice of the farmers (who typically measure the new sources against the old ones and has little faith in the new means at first). At the same time, there are some special types of new information that can be employed effectively only through particular channels.

In addition to the type of channel used, the quality of information is of vital importance since its "usefulness" is determined by several criteria which are mostly determined by the perception of the decision-maker. There are several types of knowledge and information that are irrelevant under given circumstances (the diverse social, economic and environmental conditions of the rural communities might require specific knowledge/ and competences, Knight and Wilkin, 2004), and this can be a problem for example with decision support systems based on generic models possibly offering solutions that are at variance with the farmers' own experience. Generalised information is often unsuitable, while relevant knowledge is often inaccessible to farmers since it is not converted into a consumable form, or an accessible information system. There might be asymmetries in the supply chain between the knowledge of the various players, which can even be intentional.

The main characteristics of quality information are therefore relevance, accuracy, comprehensiveness and timeliness. Of these timeliness/up-to-datedness is regarded as being the most important by many people: information that arrives late is often useless, even if it would otherwise satisfy the needs of the farmer. The timing of information is of critical importance especially in the case of daily or other shortterm decisions but less so during strategic, long-term planning.

The survey of Yongling (2004) highlights the importance of requirements towards information, stressing that poor quality, outdated, inaccurate or incomplete information poses a problem, mainly because farmers cannot distinguish between "good" and "bad" information, which the author mainly links with a low level of education. This problem is a complex one, and as such it includes one of the central issues of information management in general: that of information literacy.

\section{Working with information: information literacy}

Models used in the area of agricultural informatics confirm that in a "text book type" farm the farm manager approaches his information needs, the cost of the information and alternative sources at system level and in a systematic way, and is able to recognise information necessary for decision making. Furthermore, he consciously applies and builds the latest information technologies into his everyday work. For this reason we should have a look at information literacy, which provides an accurate description of the main characteristics of the aforementioned process.

The concept of information literacy appeared as a result of the technological development in the 1970s. In the past thirty years the term was broadened and extended with new layers of meaning added to it, while at the same time it was limited in its use (it is increasingly restricted to computer and/or Internet usage). Information literacy is not the competence to use certain devices or equipment but the skill to access and use information. 
Today most people look at information literacy as a kind of computing competence and the ability to manage information gained from the Internet (in effect, they use it for internet literacy). One of the early appearances of the "information literacy" was in 1974 (Zurkowski, 1974). The term was closely associated with educational reform (mostly that in the United States), and it was used to mean the efficient use of information already at the outset. In 1976 Burchinal (Behrens, 1994; Bawden, 2001) defined information literacy as a set of skills, dividing it into three levels: 1) skills that help to locate and use information; 2) the use of information for problem solving and decision making (as it could be seen, previous approaches focused on this level); 3) efficient and effective information location and utilisation. Later theoreticians of information literacy practically broadened and refined Burchinal's division, according to their individual concept.

Thus, the development of information literacy not only entails the use of technical tools but also the development of a way of thinking aimed at the consciously planned realisation of interests. Since information literacy means realising lack of information, looking for it, locating and processing it and then using it responsibly, it is evident that its development also includes that of critical thinking. Applied to agriculture, the truth of this statement was indicated by Öhlmer, who in the early 1990s pointed out that a tool in itself is not capable of performing a miracle and the individual using the tool plays the key role: he claims that no fundamental change takes place in information processes by computerisation since that alone only adds a certain level of comfort to these processes (Öhlmer, 1991).

Information literacy is the skill to access information and uses it for value creation, and an individual can be regarded as information literate if he recognises when he needs information. Information literacy is possessed by those who have learnt how to learn. It can be seen that information literacy requires and demands several skills from the conscious citizens of the digital world (Table 1.). Never before in human history have these skills been expected of everyone; such expectations typically concerned the members of the intellectual elite. However, since the world of today is determined by the presence, lack, value and authenticity of information and the speed of its flow, these skills have become important for everybody, including those working in agriculture.

Table 1. Information literacy skills (Source: Rab, 2008 via Eisenberg, M. \& Berkowitz, L., 1990)

Interpreting the task, identifying the information necessary for the completion of the task, and being able to determine why particular information is missing and how important it is. Formulating the question

Defining the task, realising lack of information

The strategy of acquiring information

Location and access needed to acquire the information also belongs to this skill. The information sought can be accessible in many platforms (in print, digitally, on some data storage device or even on TV); what is more, a friend or another farmer might also have it. The scale of energy input required for the acquisition of the information must be determined and whether it is in proportion to its importance.

Accessible sources must be identified: where are the necessary sources of information, how can they be accessed, when can they be used? This skill includes the competent use of the various information sources: when should information be sought in printed media and when in an online database? In agriculture the role of routinely used channels is outstanding - this is partly connected to trust and partly to less energy that needs to be invested. It is important to note that from the point of view of information strategy it represents an obstacle to finding the optimal channel.

Accessible sources must be identified. Where can these information sources be found, how can they be accessed and when can they be used? This skill includes the competent use of the various information sources: when 
should information be sought in printed media and when in an online database? ICT tools usually have an advantage in this regard: online services are accessible non-stop and at lower transaction costs.

The skill to look for information effectively in the appropriate sources belongs here. It must be recognised that the required information has been Using located, and the user must know when the search can or must be stopped. It is information important to be able to access the value (authenticity, accuracy, etc.) of the acquired information. A critical approach to assessing information might prevent the search from going off track or leading to false information. This is the dimension that Yongling (2004) also mentioned.

This is the level of analysing and working with the acquired information. Being able to analyse is not enough, but new knowledge, and understanding Synthesising must be reached. It is important to be able to display results, which in practice most often entails the understanding, comparison, combining, annotating and goal-oriented use of information, and in agriculture it is most often the best possible harmonisation of the local and the global "environments".

The highest level skill is to ensure that acquired information and processed

Evaluating knowledge is stored, retrievable and can later be used. This practically means the continuous management of our own data.

These levels are logically built on one another and entail the skill to handle information and knowledge of how to learn. The first chapter already showed the huge amount of information that needs to be tackled in agriculture for successful operation, while it must also be seen that all the six steps are not carried out in every case either by those with low or high information literacy.

As Hill (2009) states: "As individuals, farmers have their favoured information sources, which they use depending on the specific information being sought. The amount of information collected depends on the complexity of the task and the importance of the decision." The context, the channel, the type of information, the access to information and the farmer's experience and personal preferences are in close relation. Therefore, information flow must be studied in its complexity, at different levels and in detail. (e.g. Fountas et al., 2006; Nash et al.,2009). The significant differences between European farms (in regard to size, type, culture and numerous other factors) each influence decision making processes and information strategies (e.g. Öhlmer et al., 1998).

\section{Information literacy, ICT and the diffusion of innovation in agriculture}

"The importance of the Internet is growing, both as a source of information and as a vehicle for transactions. It is likely that businesses working outside this system will lose competitiveness"

"Information management may become easier, timelier, and generally provide greater value through computerised information system use."

Harkin's research (s.a.) shows that the diffusion of ICT opens up the following opportunities. Information technologies are regarded in the following list as mediating channels and a vehicle for new services.

- timelier, more comprehensive information

- accessing a new type of information

- several competing information sources

- single window access

- easy exchange and discussion of information ideas

- easier cooperation and access to other farmers and experts 
Despite these "common" opinions, ICT take-up in agriculture remains low. It is important to research the various aspects of adoption of new information technology, and also not only the use, but the "effective use" of it (Gurstein, 2003). It is important to distinguish between the opportunities for digitallyenabled activity presented by ICT access from the actual realization of those opportunities in the form of "effective use".

It goes without saying that a region cannot be characterised in a single dimension but only from the perspective of farming, and this is also true for a family making their living from agriculture in a given rural area. This is indicated by the last two bullet points of the above list which are especially noteworthy in cases where great distances can be bridged thanks to IT services offered in the areas of eGovernment, eHealth or eLearning. Several studies on the Internet and information technology have established the importance of other characteristics (e.g. having children in a farming family) in regard to ICT take-up, but the literature of agricultural informatics also often mentions the positive influence of a workplace outside the farm on ICT use.

In addition, the five factors established by Rogers as influencing the diffusion of innovation also play an important part. Rogers (1962) defines several intrinsic characteristics of innovations that influence an individual's decision to adopt or reject an innovation. The relative advantage is how improved an innovation is over the previous generation. Compatibility is the second characteristic, the level of compatibility that an innovation has to be assimilated into an individual's life. The complexity of an innovation is a significant factor in whether it is adopted by an individual. If the innovation is too difficult to use an individual will not be likely to adopt it. The fourth characteristic, trialability, determines how easily an innovation may be experimented with as it is being adopted. If a user has a hard time using and trying an innovation, this individual will be less likely to adopt it. The final characteristic, observability, is the extent to which that an innovation is visible to others. An innovation that is more visible will drive communication among the individual's peers and personal networks and will in turn create more positive or negative reactions."

According to Offer (2005), the perceptible profit might be the greatest obstacle or promoter of ICT take-up in agriculture, along with the proportion in the use of resources required and the realisable advantages. Systems and information sources are not expected to offer the benefits dreamed up by their designers but instead to satisfy the needs of their users, which leads on to the issue of compatibility. Nuthall's research in 2004 established that computer use does not guarantee increased profitability. The situation, however, is more complex than this. It cannot be excluded that in the Australian farms he studied the tools of "mental management" could have produced the same growth. At the same time numerous farmers he surveyed said that they found the computer useful and that the newly adopted practice of data collection and systematisation had a tangible impact on their previous decision making processes (Nuthall, 2004). In this case the relative advantage offered by ICT use was primarily a relative and not a directly economic one. It must be noted here that of all the economic benefits afforded by ICT use literature primarily focuses on transaction costs.

Another finding by Nuthall is that the diffusion of solutions better suited to already existing information management systems is faster, thus highlighting the importance of compatibility. Furthermore, if the use of an ICT tool brings advantages for an individual, there is a greater chance that those in his environment will chose the new solution. This calls attention to the importance of observability.

Another potential source of problem with currently used agricultural IT management systems is interoperability, i.e. transferring information between systems, which mainly raises the problem of excessive complexity, which is accompanied by the lack of user-centeredness in development guidelines applied to the design of IT and decision support systems. 
The community aspect and interactivity (resulting from the fundamentally communication-based nature of Rogers's diffusion of innovations theory) is manifested in observability and triability (there are several examples of the latter in agriculture: for example, basic ingredient manufacturers often provide product samples for farmers). Networks and various partnerships serve as an important domain for seeking and selecting information (Colliver, 2001). Similarly, farmers' learning processes are predominantly more efficient in groups (Kilpatrick et al, 2003). As active members of a group individuals adopt new innovation easier, which is not surprising since they are in effect the starters of the Rogers diffusion process. "Open-minded" farmers (or those who actively seek information (events, consultants, clubs, periodicals) are more likely to use the Internet. Farmers who are fully information literate are bound to use the Internet with the only differences being perceptible in regard to the pattern and intensity of use. They are the starting point of the diffusion of ICT use.

Based on Harkin, Offer and others it can be concluded that since the late 1970s and early 1980s service and technology developers have been making the same mistake, i.e. they fail to satisfy user needs, which is a key challenge in the area. Access to information/knowledge must be made more flexible, which should include gathering information about the potential users' needs and problems as well as offering them consultation opportunities. This problem is not specific to agricultural IT developments since it spans the close to ten years (i.e. almost the entire period) of European eGovernment development projects for example.

Farmers have not yet been encouraged as obviously and successfully to change their approach to information management as it could have been expected based on the technical "potentials" (Nuthall, 2006). Nuthall also points out that since the farmer is an essential component in the "information system" of a farm, the decision to use ICT often depends on the personal characteristics of the farmer, such as his or her personality, experience, age, education, goals and objectives.

\section{The aspects of using ICT in farm management}

Alvarez and Nuthall (2006) summarised earlier literature and tried to set up a model in which they collected the factors influencing the adoption of new software (Figure 2.).

Mainly based on Apps and Iddings (1990) as well as Taragola and Van Lierde (2010), a more detailed picture can be drawn:

- Farmer's characteristics (age, experience, personality, education)

- Community culture (network, associations)

- Farm characteristics (size, type, geography)

- Goals and objectives (attitude towards learning)

- Decision making and information management style (time, information sources ( number, intensity in use), extension usage, support from the outside)

- Other element: trust

As a rule of thumb, based on Nuthall it can be stated that with great probability farmers will keep seeking and collecting information until they actually feel that the cost incurred by continuing the search will exceed the benefits that can be secured by the information attained. However, this "marginal utility" approach is made more complex if we consider the knowledge base and experience of a farmer at any given time (e.g. if we apply this logic young farmers might need more information). At the same time it must be remembered that since it is difficult to attach economic value to information, the search process will mostly depend on the perception of the farmers, which means that the proportion of intuitive decisions is likely to increase significantly with experience (at least under the given circumstances). 


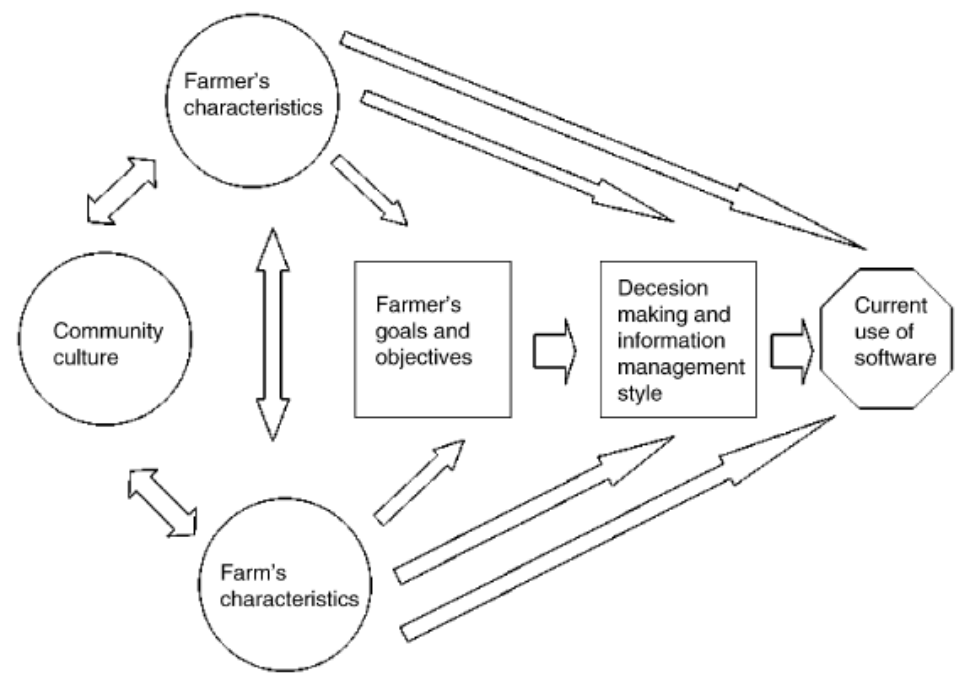

Figure 2. The factors influencing the adoption of new software (Alvarez and Nuthall, 2006)

Based on the above and what has been said prior to this, for those farmers who are open to learning and have no gap in their knowledge in regard to the applications (i.e. shares the opinion of the developers about the given system) and clearly take advantage of the use of the given application a straight path leads to IT use.

\section{Conclusion}

Surprisingly enough, the factors influencing ICT use have barely changed in the last 30 years, since personal computers have become commercially available. More or less one can find the same old stories regarding computers, decision support systems (DSS) and internet-usage: the background of the farmer (demographic and other variables), the characteristics of the farm (size, complexity etc.), the cultural background and the local community. Every farm is different and the information strategy of every farmer is different so it is really hard to find solutions that fit in with the processes of the majority of the farms and farmers. One size does not fit all or even come anywhere close to it.

If ICT use is not coupled with critical thinking and a clear concept, the desired results and a positive impact on farm management cannot be achieved, what is more, damage can be caused as happened in the case of industrial methods adopted without a critical approach. One of the key issues in regard to the diffusion of IT applications is the assessment of the information needs at any given time (Rockart, 1979). Only by targeting these needs (possibly after latent needs are explored and defined) can developments bring success. If this is accompanied by easy usability, trust and economic advantages, it can be expected that these applications and tools will be used, however, the characteristics of the given farm and the personal characteristics and attitude of the farm manager will play a significant role.

The above focuses attention on the fact that the study of these phenomena must be carried out in the given environment: just as agriculture is inseparable from the soil and the place, the exploration of information-intensive agriculture is mainly a local, regional and country-wide task, since several cultural, legal and historical factors come into play at these levels.

After carefully considering past experiences it must be said that in order to finally fulfil the potential of communication technology (and speed up information processes) we have to use the oft cited user-centric approach during the development of new applications, involving the farmers (bottom up) or at least define user groups or information patterns of farmers in a country or a region. One thing cannot be forgotten: there always will be farmers who can not adopt ICT for various reasons (not perceived usefulness, 
complexity, preferring different information channels etc. etc.) even if it looks like it would be an advantage for them. There are other ways for them to utilise the benefits of the technology, for example through intermediaries (Csótó and Herdon, 2009). ICT-usage among farmers can be the way but not the goal itself.

To sum up, information-intensive agriculture is fundamentally determined by information, knowledge and the decision-making farmers, in effect the human factor; therefore, studies aimed at the improvement of the situation of agriculture with ICT tools must be centred on the human element (and information).

\section{References}

Alvarez, J., Nuthall, P. 2006. Adoption of computer-based information systems: The case of dairy farmers in Canterbury, NZ, and Florida, Uruguay. Computers and Electronics in Agriculture, 50(1), 48-60.

Bawden D. 2001. Information and digital literacies: a review of concepts (Journal of Documentation. vol. 57, no. 2, March 2001, 218-259.)

Behrens, S. J., 1994. A conceptual analysis and historical overview of information literacy. College and Research Libraries, 55(4), 309-322.

Colliver, R. 2001. Building Networks. Report for the 'Working the Networks' Project. Department of Agriculture, Western Australia, Perth, Australia.

Csótó M., Herdon M. 2009. The Role of Intermediaries in the Success of Electronic Claiming for Farm Subsidies in Hungary. In: 7th World Congress on Computers in Agriculture and Natural Resources. Zazueta F. S., Jiannong Xin ed. Reno (Nevada), USA, 2009.06.22-2009.06.24. Michigan: American Society of Agricultural Engineers, 117-120.

Eisenberg, M., Berkowitz, L. 1990. Information problem-solving. New Jersey: Ablex.

Fountas S., Wulfsohn D., Blackmore B.S., Jacobsen H.L., Pedersen S.M. 2006. A model of decision-making and information flows for information-intensive agriculture Agricultural Systems 87 (2006) 192-210.

Gladwin C.H. (editor) 1989. Ethnographic Decision Tree Modeling, Sage Publications

Gurstein, M. 2003. Effective use: A community informatics strategy beyond the Digital Divide In: First

Monday, Volume 8, Number 12 - 1 December 2003 Available at:

http://firstmonday.org/htbin/cgiwrap/bin/ojs/index.php/fm/article/view/1107/1027

Harkin, M (sine anno): ICT Adoption as an Agricultural Information Dissemination Tool - An historical perspective http://departments.agri.huji.ac.il/economics/gelb-harkin-3.pdf Downloaded: 10th September 2010.

Herdon M. 2009. Impacts of e-collaboration tools for development of rural areas. In: AVA Congress 4: International Congress on the Aspects and Visions of Applied Economics and Informatics. Nábrádi A., Lazány J., Fenyves V. ed. Debrecen, Magyarország, 2009.03.26-2009.03.27. Debrecen: Agroinform Kiadó, 952-959.(ISBN:978-963-502-897-9)

Iddings, R., Apps, J. 1990. What influences farmers' computer use? J. Ext. 28 (1), 19-21.

Kilpatrick, S., Bond, L., Bell, R., Knee, J., Pickard, G. 2003. Effective farmer groups for defining best practices for sustainable agriculture. Published online at In: Vanclay, F., Fulton, A. (Eds.), Extending Extension: Beyond Traditional Boundaries, Methods andWays of Thinking. Proceedings of the Austrasia Pacific Extension Network 2003 National Forum, Tasmania, Available at: http://www.regional.org.au/au/apen/2003

Knight J.D., Wilkin D.R. 2004. A novel method for the delivery of information on the storage of malting barley Computers and Electronics in Agriculture 44 (2004) 133-144.

Nash, E., Dreger, F., Schwarz, J., Bill, R., Werner, A. 2009. Development of a model of data-flows for precision agriculture based on a collaborative research project. Computers and Electronics in Agriculture 66 (1), 25-37.

Niederhauser, N, Oberthu T, Kattnig S., Cockj. 2008. Information and its management for differentiation of agricultural products: The example of specialty coffee In: Computers and electronics in agriculture 61 (2008) 241-253. 
Nuthall, P.L. 2004. Case studies of the interactions between farm profitability and the use of a farm computer In: Computers and Electronics in Agriculture 42 (2004) 19-30 .

Offer, A., 2005. Introduction - computers and farming: vision and reality? In: Gelb, E.,Offer, A. (Eds.), ICT in Agriculture: Perspectives of Technological Innovation (online) Available at: http://departments.agri.huji.ac.il/economics/gelb-table.html .

Öhlmér, B., 1991 On-farm computers for farm management in Sweden: potentials and problems In: Agricultural Economics, Volume 5, Issue 3, July 1991, Pages 279-286

Öhlmer, B., Olson, K., Brehmer, B., 1998. Understanding farmers' decision making processes and improving managerial assistance. Agricultural Economics 18, 273-290.

Öhlmér, B. 2001. Analytic and intuitive decision making - Swedish farmers' behavior in strategic problem solving. In: Proceedings of the Third EFITA Conference, Montpellier, France.

Rab, Á. 2008. Digital culture - Digitalised culture and culture created on a digital platform In: Information Society From Theory to Political Practice. Coursebook, 183-201. Pintér R. ed. Gondolat - Új Mandátum, Budapest

Rockart, J., 1979. Chief Executives Define Their Own Information Needs. In: Harvard Business

Rogers, E.M. 1962. Diffusion of Innovations. The Free Press. New York.

Sörensen C.G., Pesonen L., Fountas S., Suomi P., Bochtis D., Bildsře P., Pedersen S.M., 2010 A user-centric approach for information modelling in arable farming In: Computers and Electronics in Agriculture 73 (2010) 44-55

Taragola N.M. , Van Lierde D.F. 2010. Factors affecting the Internet behaviour of horticultural growers in Flanders, Belgium Computers and Electronics in Agriculture 70 (2010) 369-379

Zurkowski, P. G., 1974. The Information Service Environment: Relationships and Priorities, National Commission on Libraries and Information Science, Nov 1974, ED100391.

Yongling, Z. 2004. Information service in rural China field surveys and findings. Bangkok: FAO. 